\title{
Effects of Biochar Application and Irrigation on Soil Preferential Flow and Winter Wheat Productivity
}

\author{
Xin Cong ${ }^{1}$, Sifang Zhou ${ }^{2}$, Tong Wang ${ }^{2}$, Guibin Pang ${ }^{1}$, Zhenghe $\mathrm{Xu}^{1 *}$ \\ ${ }^{1}$ College of Water Conservancy and Environment, University of Jinan, \\ Jinan, Shandong, 250022, People's Republic of China \\ ${ }^{2}$ Shandong Hydrology and Water Environment Technology Co., Ltd, \\ Jinan, Shandong, 250014, People's Republic of China
}

Received: 19 February 2021

Accepted: 17 June 2021

\begin{abstract}
Biochar has been extensively used for the improvement of soil environment in fields. However, the effects of biochar on soil water movement and crop productivity under different irrigation rates were not well clear or consistent. The objectives of this study were to investigate whether biochar could prevent the production of preferential soil flow, and to study the effects of biochar and irrigation on soil properties, nutrient leaching, crop growth and yield, which was of great significance to improve crop water and fertilizer use efficiency and protect the ecological environment. The experiments included two parts, i) short-term blue dye tracer test, to investigate the effect of biochar application (20 and $40 \mathrm{t} / \mathrm{hm}^{2}$ ) on the degree of preferential flow, and ii) a field trial with winter wheat (Triticum aestivum L.) as test material was conducted in the lysimeters in 2018-2019, to investigate the effect of biochar application $\left(20 \mathrm{t} / \mathrm{hm}^{2}\right)$ on the soil nitrate nitrogen distribution and wheat yield under two irrigation rates ( 0.6 reference crop water requirement $(E T), 0.8 E T)$. The results showed that i) within the designed biochar application rates, the degree of preferential flow was decreased with the increase of biochar application, but the decreasing speed slowed down significantly, with the preferential flow fraction $\left(P_{F-f r}\right)$ reduced by $6 \% \sim 17.5 \%$, especially under high irrigation, ii) compared with the control treatment, biochar improved the capacity of the soils to retain nutrients, alleviated the negative effect of water shortage, and increased winter wheat productivity. Our results suggested that the $0.8 E T_{c}$ irrigation and $20 \mathrm{t} / \mathrm{hm}^{2}$ biochar was recommended in the field condition.
\end{abstract}

Keywords: biochar, soil preferential flow, winter wheat, water and fertilizer utilization efficiency, yields

*e-mail: xu4045@126.com 


\section{Introduction}

As a high-yield agricultural area in China, excessive irrigation and nitrogen application is common in North China Plain in order to meet the high-yield demand $[1,2]$. It was reported that under the climate soil conditions in North China Plain, the nitrate nitrogen leaching out of $1.0 \mathrm{~m}$ root zone can reach $209 \mathrm{~kg} / \mathrm{hm}^{2}$ per year in terms of the conventional nitrogen application rate of farmers in winter wheat summer maize rotation [3]. It was found that most of nitrate nitrogen would be rapidly infiltrated through preferential flow, and the average contribution rate of preferential flow to nitrate nitrogen leaching was about $71 \%$ [4]. Preferential flow is a common form of soil water movement, and previous studies have shown that $60 \sim 70$ percent of the total water flux can occur through preferential flow [5]. Macropores in the soil lead to preferential flow, which leads to the rapid flow of soil water in the field, thus reducing the availability of water and nutrients and causing groundwater pollution. So, the study of the reduction of preferential flow is of great significance for reducing environmental pollution and improving soil water and nutrient utilization.

The research of preferential flow at home and abroad mainly focuses on the mechanism and function of preferential flow under various external natural conditions, as well as various technical means used in the research of preferential flow, such as, the change of priority flow in different spatial scales [6], the influence of rainfall and irrigation on soil preferential flow [7]. In the research method, previous studies have shown that the dye tracer infiltration experiment is an effective way to visualize infiltration patterns and monitor preferential flow [8]. Among, Brilliant Blue FCF is widely used in visualization of flow paths in natural soil systems, as it can achieve a good compromise between visibility, mobility, and toxicity [9]. But, there are relatively few studies on how to control preferential flow, reduce nutrient loss and reduce environmental pollution.

At present, exploring the water and fertilizer status in the process of wheat planting has become a hot issue in the field of agricultural production in recent years. Among them, water management is a reliable technical measure to prevent and control the loss of water and nutrients [10]. Meanwhile, there has been an increasing interest in using biochar to improve crop water and fertilizer use efficiency. Biochar is a carbon-rich substance produced by burning any organic compound through the pyrolysis process. A large number of studies have shown that application of biochar can improve soil physical, chemical, and biological characteristics such as bulk density, hydrological properties, aggregate structure, ion exchange capacity, and microbial activity, as well as enrich mineral nutrients [11, 12], but how it affects the field soil water movement process is rarely reported. At the same time, research about the leaching of biochar on crop yield and nutrients is mainly concentrated on the indoor soil column leaching simulation and pot experiment [13], however, less research on the field.

Therefore, in this study, the winter wheat (Triticum aestivum L.) field in the semi-arid area of North China Plain was taken as the research object. We tested the validity of the following hypothesis: (1) biochar application will reduce preferential flow, and (2) biochar application will improve water and fertilizer use efficiency and yield of winter wheat in comparison to the non-amended controls. Through the field dyeing tracer experiment, combined with the image morphology analysis theory, and using the statistical analysis method, the characteristics of soil preferential flow in winter wheat field with and without biochar under different irrigation rates were studied, which could provide theoretical support for revealing whether biochar can prevent the preferential flow. Meanwhile, the effects of different combinations of irrigation and biochar on soil properties, distribution of water and nitrogen, leaching status and growth of winter wheat were studied by field plot experiment. The results provide a theoretical basis for biochar to improve crop water and fertilizer use efficiency and control non-point source pollution.

\section{Material and Methods}

\section{Study Site}

The experiments were conducted at Shandong Irrigation Test Center Station $\left(36^{\circ} 34^{\prime} \mathrm{N}, 116^{\circ} 50^{\prime} \mathrm{E}\right)$, which is located in the Jinan, Shandong Province, China (Fig. 1). The soil texture was a loam (USDA, 2005). Meteorological parameters were collected every five minutes by an automatic weather station installed close to the experimental field. The annual rainfall was $654.7 \mathrm{~mm}$, the mean annual potential evapotranspiration was $1399.70 \mathrm{~mm}$ and the mean annual temperature was $14.3^{\circ} \mathrm{C}$ (computed over the period 2008 2018), the precipitation and temperature in winter wheat growing season were shown in Fig. 2. The bulk density ranged from 1.40 to $1.67 \mathrm{~g} / \mathrm{cm}^{3}$ and the total porosity was between $48.7 \%$ and $54.2 \%$. Soil organic matter content varied from $1.04 \%$ to $1.32 \%$. The $\mathrm{TN}$, available $\mathrm{P}$ and available $\mathrm{K}$ in $0 \sim 200 \mathrm{~mm}$ soil layer was $1.07 \mathrm{~g} / \mathrm{kg}, 22.26 \mathrm{mg} / \mathrm{kg}$ and $83.98 \mathrm{mg} / \mathrm{kg}$, respectively.

\section{Dye-Tracer Experiments and Image Analysis}

\section{Tracer Experiment}

The experimental design included 3 biochar rates $\left(0,20\right.$ and $\left.40 \mathrm{t} / \mathrm{hm}^{2}\right)$, which were recorded as B0, B2, and $\mathrm{B} 4$, and 3 irrigation rates $(40,54$ and $68 \mathrm{~mm})$, which were recorded as I1, I2, and I3. The experiments consisted seven treatments including I1B0, I2B0, I2B2, I2B4, I3B0, I3B2, and I3B4, each with three replicates. Before planting winter wheat, we randomly selected one 

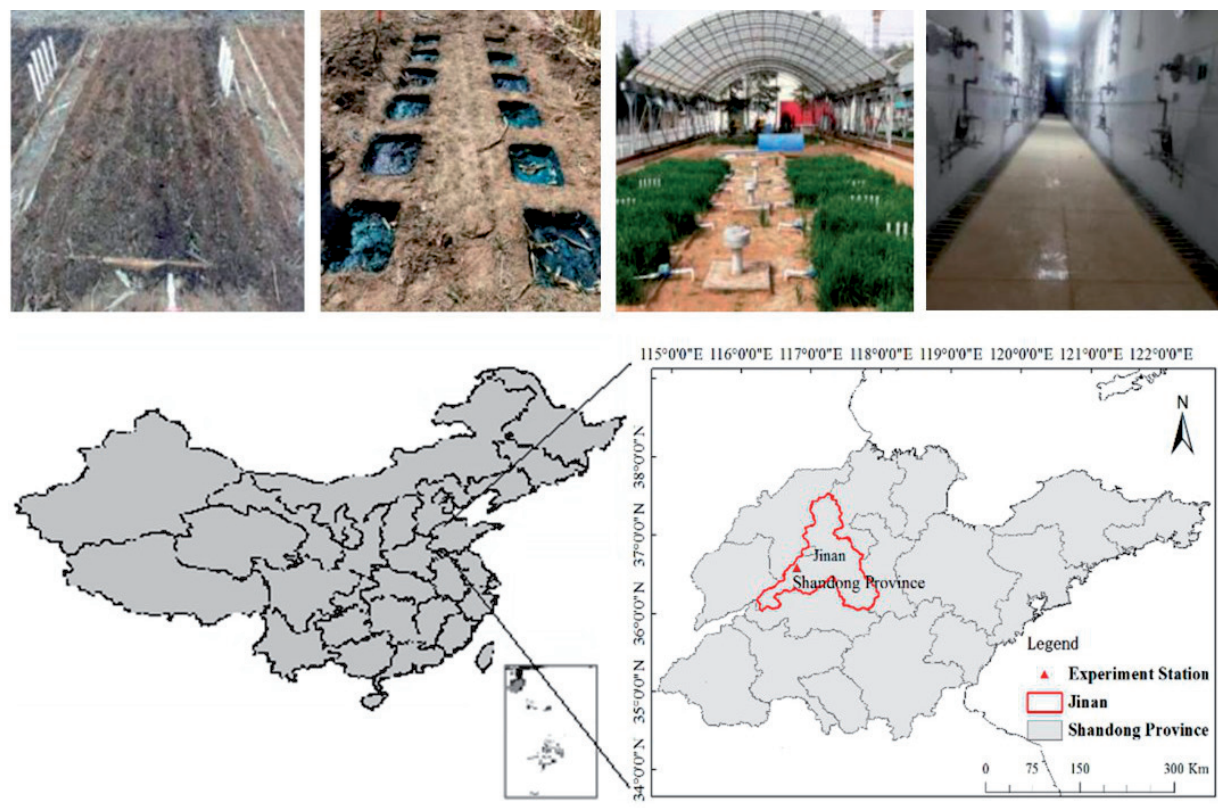

Fig. 1. Location of the experimental station.

site at each of the 21 plots $(0.5 \mathrm{~m} \times 0.5 \mathrm{~m})$ for rainfall simulations and dye experiments. The plots were more than $0.3 \mathrm{~m}$ apart. The biochar applied in the field experiment is a commercial charcoal obtained from corn stalk through a slow pyrolysis process at temperature of $500^{\circ} \mathrm{C}$ under the condition of hypoxia. The $\mathrm{pH}$ of the selected biochar was 9.48, total carbon was $698.56 \mathrm{~g} / \mathrm{kg}$, organic matter was $107.21 \mathrm{~g} / \mathrm{kg}$, total nitrogen, available $\mathrm{P}$ and $\mathrm{K}$ was $12.35 \mathrm{~g} / \mathrm{kg}, 385.96 \mathrm{mg} / \mathrm{kg}$ and $801.35 \mathrm{mg} / \mathrm{kg}$, specific surface area was $72.64 \mathrm{~m}^{2} / \mathrm{g}$, and bulk density was $0.27 \mathrm{~g} / \mathrm{cm}^{3}$. The pore size of biochar was smaller than $1 \mathrm{~mm}$. Before the start of the experiment, biochar was evenly spread on the soil and stirred repeatedly, and mixed evenly with $0 \sim 20 \mathrm{~cm}$ soil. Afterward, 10.0 L, 13.5 L, and 17.0 L of the mixed solution containing Brilliant Blue FCF (4.0 g/L) was uniformly sprayed to the top soil surface within the water pump and no visible ponding occurred during the entire tracer application period. Next, the dyed area was covered by a piece of canvas to prevent evaporation and rainfall infiltration. After $24 \mathrm{~h}$, the canvas was carefully removed. Afterward, vertical soil profiles were excavated at the dyed area. Based on the depth of dyed soil profiles, all soil profiles were excavated to a depth of $0.5 \mathrm{~m}$. To avoid any boundary effect, four vertical profiles were collected starting at $100 \mathrm{~mm}$ from one edge with a lateral increment of $1.0 \mathrm{~m}$ at each plot, as shown in Fig. 1. After excavation, each vertical profile was trimmed by a flat-headed shovel. Subsequently, the exposed vertical profiles with a size of $0.5 \mathrm{~m} 0.5 \mathrm{~m}$ were photographed and corrected for geometric distortion according to the edge points marked by rulers.

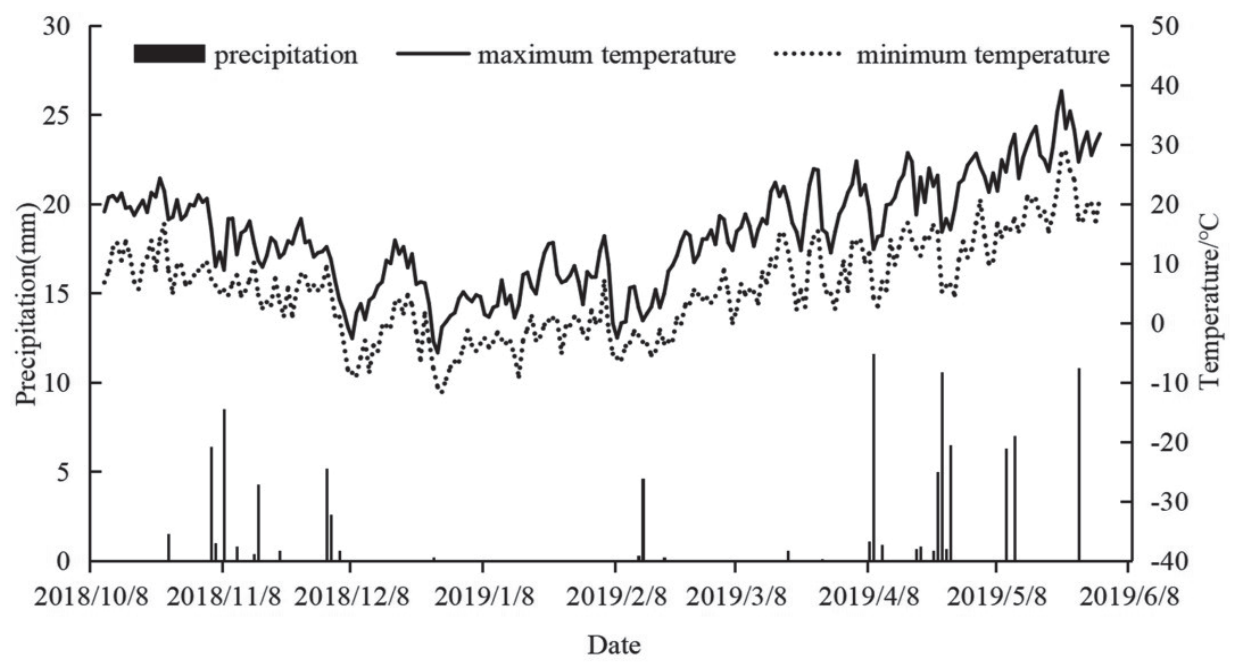

Fig. 2 Daily rainfall and temperature during the winter wheat growing season. 


\section{Image Analysis and Preferential Flow Indices}

Image analysis was carried out using a combination of Adobe Photoshop CS6 and Image-Pro plus 6.0. First, we used Adobe Photoshop CS6 to make geometric corrections, and then adjust color, subtract the background according to Koch, Kahle, and Lennartz [14], and converted the adjusted images into binary images using Image-Pro plus 6.0 (Fig. 3). Finally, we used the stained parts of the binary images to calculate the number of stained pixels per depth, then exported the output data to Excel 2010. To characterize the dye pathways in the vertical soil profiles, we used the output data to calculate the following parameters to quantify the degree of preferential flow: the maximum depth of soil water infiltration $\left(D_{\max }\right)$, dye coverage $\left(D_{c}\right)$ [15] which was defined as the percentage ratio of the dye-stained area to the total profile area, preferential flow fraction $\left(P_{F-f r}\right)$ [16] defined as the fraction of the total percolation that flows along preferential flow pathways, uniform infiltration depth $\left(U_{n i f}\right)$ [17] defined as the depth at which dye coverage decreases below $80 \%$, which represents the depth of the uniform infiltration front.

\section{Field Experiments and Test Indicators}

\section{Experimental Design and Treatments}

Based on tracer experiment, the field experiments design included 2 biochar application rates $\left(0 \mathrm{t} \mathrm{hm}^{-2}\right.$ (B0) and $20 \mathrm{t} / \mathrm{hm}^{2}$ (B2)) and 2 irrigation levels (300 mm (0.6 reference crop water requirement $(E T)$, IL) and $\left.370 \mathrm{~mm}\left(0.8 E T_{c}, \mathrm{IH}\right)\right)$. There were four treatments in total (ILB0, IHB0, ILB2, and IHB2), each with 3 replicates. Different treatments were arranged in a randomized block design. The plot size was $6.67 \mathrm{~m}^{2}$ $(2 \times 3.335 \mathrm{~m})$ including 5 rows spaced at $0.2 \mathrm{~m}$. Biochar was incorporated into the soil using a chisel plow tiller to $0.2 \mathrm{~m}$ depth. Wheat cultivar (Shannong 28) was sown at the rate of $130 \mathrm{~kg} / \mathrm{hm}^{2}$. The field was irrigated with $35 \mathrm{~mm}$ of water prior to sowing in order to ensure wheat germination. The precipitation during the growth period of winter wheat is $100.5 \mathrm{~mm}$. Using a precise water meter, the first irrigation $(90 \mathrm{~mm})$ was supplied on March 12 (the jointing stage, 147 days after sowing), the second irrigation $(75 \mathrm{~mm})$ was supplied on April 13 (the heading stage, 179 days after sowing), and the third irrigation ( 0 or $70 \mathrm{~mm}$ ) was supplied on May 8 (the grain filling stage, 204 days after sowing). The percolation filter was used to collect the soil leaching solution. There were five pipes with different depths in the test pit, which could connect the leachate of different depths in the soil. The outlet of the pipeline was equipped with a valve, which could be opened to collect drainage water. According to the amount of fertilizer applied by local farmers, $150 \mathrm{~kg}$ $\mathrm{P}_{2} \mathrm{O}_{5} / \mathrm{hm}^{2}$ and $150 \mathrm{~kg} \mathrm{~K} / 2 \mathrm{O} \mathrm{hm}^{2}$ were applied as the basal fertilizer. Phosphate and potassium fertilizers were superphosphate (containing 12\% $\mathrm{P}_{2} \mathrm{O}_{5}$ ) and potassium chloride (containing $60 \% \mathrm{~K}_{2} \mathrm{O}$ ), respectively. For $\mathrm{N}$ fertilizer, the application rate was $255 \mathrm{~kg} \mathrm{~N} / \mathrm{hm}^{2}$, urea was split-applied with $50 \%$ as basal, $50 \%$ at jointing stage. The wheat was sowing on October 17 in 2018 and hand-harvested on June 1 in 2019.

\section{Soil Sampling and Analysis}

Five days after irrigation/harvesting, soil water content $(S W C)$ was recorded using a time domain reflectometry (TDR) meter. Soil sampling was conducted at $0.2 \mathrm{~m}$ intervals to a depth of $1.0 \mathrm{~m}$. Disturbed soil samples were stored in a plastic bag, undisturbed soil samples were taken in a metal ring, then transported to the laboratory. The field capacity $(F C)$ was determined with the Wilcox Method (Cutting Ring Method) [18]. Bulk density $(B D)$ was calculated from ring samples as the ratio of oven dry mass to sample size [19]. The sodium acetate flame photometric method was selected to determine the cation exchange capacity $(C E C)$ [20]. The soil organic carbon $(S O C)$ was determined with the potassium dichromate volumetric method [21]. Soil total porosity was determined by flume immersion method according to Zhu [22]. Soil organic matter was determined by heating digestion of soil organic matter with $5 \% \mathrm{~K}_{2} \mathrm{Cr}_{2} \mathrm{O}_{7}$ and $\mathrm{H}_{2} \mathrm{SO}_{4}$ [23]. The TN contents in soil samples was determined by the Kjeldahl method [24]. The soil available $\mathrm{K}$ was quantified using $1 \mathrm{~mol} / \mathrm{L}$ of ammonium acetate extraction-flame photometry. In addition, soil $\mathrm{NO}_{3}^{-}-\mathrm{N}$ and available $\mathrm{P}$ contents were analyzed using spectrophotometric methods with phenol disulfonic acid and molybdenum blue-ascorbic acid method, respectively [25]. All analyses were conducted in triplicate.

The residual $\mathrm{NO}_{3}^{-}-\mathrm{N}$ accumulation $\left(N, \mathrm{~kg} / \mathrm{hm}^{2}\right)$ in the $1.0 \mathrm{~m}$ soil profiles was calculated using Eq. (1):

$$
N=\sum N_{\mathrm{i}}=A \times 10^{-3} \times \sum\left(C N_{\mathrm{i}} \times B D_{\mathrm{i}}\right) \times H_{i}
$$

...where $N_{i}(\mathrm{mg} / \mathrm{kg})$ is $\mathrm{NO}_{3}^{-}-\mathrm{N}$ content in the $i$ soil layer, $C N_{i}(\mathrm{mg} / \mathrm{kg})$ is $\mathrm{NO}_{3}{ }^{-} \mathrm{N}$ content in the $i$ soil layer, $B D_{i}\left(\mathrm{~g} / \mathrm{cm}^{3}\right)$ is soil bulk density of the $i$ soil layer, $H_{i}(\mathrm{~m})$ is the $i$ soil layer thickness, $A\left(10000 \mathrm{~m}^{2}\right)$ is the land area per hectare, $i$ refers to the soil layer at the depth of $0 \sim 1.0 \mathrm{~m}$.

$\mathrm{NO}_{3}^{-}-\mathrm{N}$ leaching loss $\left(L N, \mathrm{~kg} / \mathrm{hm}^{2}\right)$ was calculated using Eq. (2):

$$
L N=\sum_{\mathrm{i}=1}^{\mathrm{n}} \frac{C N_{L i} \times V_{i}}{S} \times 0.01
$$

...where $C N_{L i}(\mathrm{mg} / \mathrm{mL})$ is $\mathrm{NO}_{3}^{-}-\mathrm{N}$ content in the leaching solution, $n$ is the leaching times, $V_{i}(\mathrm{~mL})$ is the volume of leaching solution (deep percolation), $S\left(\mathrm{~m}^{2}\right)$ is the plot size.

Nitrogen partial factor productivity (NPFP, $\mathrm{kg} / \mathrm{kg}$ ) was calculated as 


$$
N P F P=Y / F_{N}
$$

...where $Y\left(\mathrm{~kg} / \mathrm{hm}^{2}\right)$ is the yield, $F_{N}$ is the total nitrogen content of applied nitrogen fertilizer $\left(\mathrm{kg} / \mathrm{hm}^{2}\right)$.

\section{Grain Sampling}

At maturity, aboveground biomassand (BD) and the yield components were measured, then the yield was calculated. The estimation of yield was based on a sample of $1.0 \mathrm{~m}^{2}$ per plot, which was calculated using Eq. (4):

$$
Y=E P \times S G \times T K W \times 10^{-2}
$$

...where $Y\left(\mathrm{~kg} / \mathrm{hm}^{2}\right)$ is the yield, $E P$ (ear) is the effective panicles per square meter, $S G$ (grain) is the grain number per spike, and $T K N(\mathrm{~g})$ is the thousand kernel weight.

\section{Evapotranspiration (ET) and Water Use Efficiency} (WUE)

The $E T_{c}(\mathrm{~mm})$ was calculated using the soil water balance Eq.

$$
E T_{c}=P_{r}+U+I-D-R-\Delta W
$$

...where $P_{r}(\mathrm{~mm})$ is the effective rainfall, $U(\mathrm{~mm})$ is the recharge of underground water, $I(\mathrm{~mm})$ is the irrigation, $D(\mathrm{~mm})$ is the depth of percolation, $R(\mathrm{~mm})$ is the runoff, $\Delta W(\mathrm{~mm})$ is the difference of soil moisture content for the $0 \sim 1.0 \mathrm{~m}$ between planting and maturity stage.

The test pit has a bottom and no runoff was generated during the growing season, so $U$ and $R$ were neglected. Eq. (5) could thus be simplified as:

$$
E T_{c}=P_{r}+I-D-\Delta W
$$

$W U E\left(\mathrm{~kg} / \mathrm{hm}^{2} / \mathrm{mm}\right)$ was calculated using Eq. (7):

$$
W U E=Y / E T_{c}
$$

\section{Statistical Analysis}

Data were analyzed in Excel 2010 and SPSS 20.0 statistical program (Chicago, USA). Two-way analysis of variance (ANOVA) was performed with the general linear model procedure to calculate the effects of biochar levels and irrigation water level on the investigated parameters. When the $F$-value was significant, a multiple means comparison was carried out using the least significant difference (LSD). The difference between treatments was deemed significant if the observed significance $P$ value was less than 0.05 .

\section{Results}

\section{Effect of Biochar on Preferential Flow Morphology}

The dye-stained images indicated apparent differences between treatments with different biochar application rates under the condition of the same irrigation (Fig. 3). Matrix flow dominated in soil profiles of B4, but preferential flow was apparent in the B0 treatment. This showed that in the process of field seepage, the phenomenon of preferential seepage occurred in the soil surface because of the root system and biological activities. The trends of $U_{n i f}$ and $P_{F-f r}$
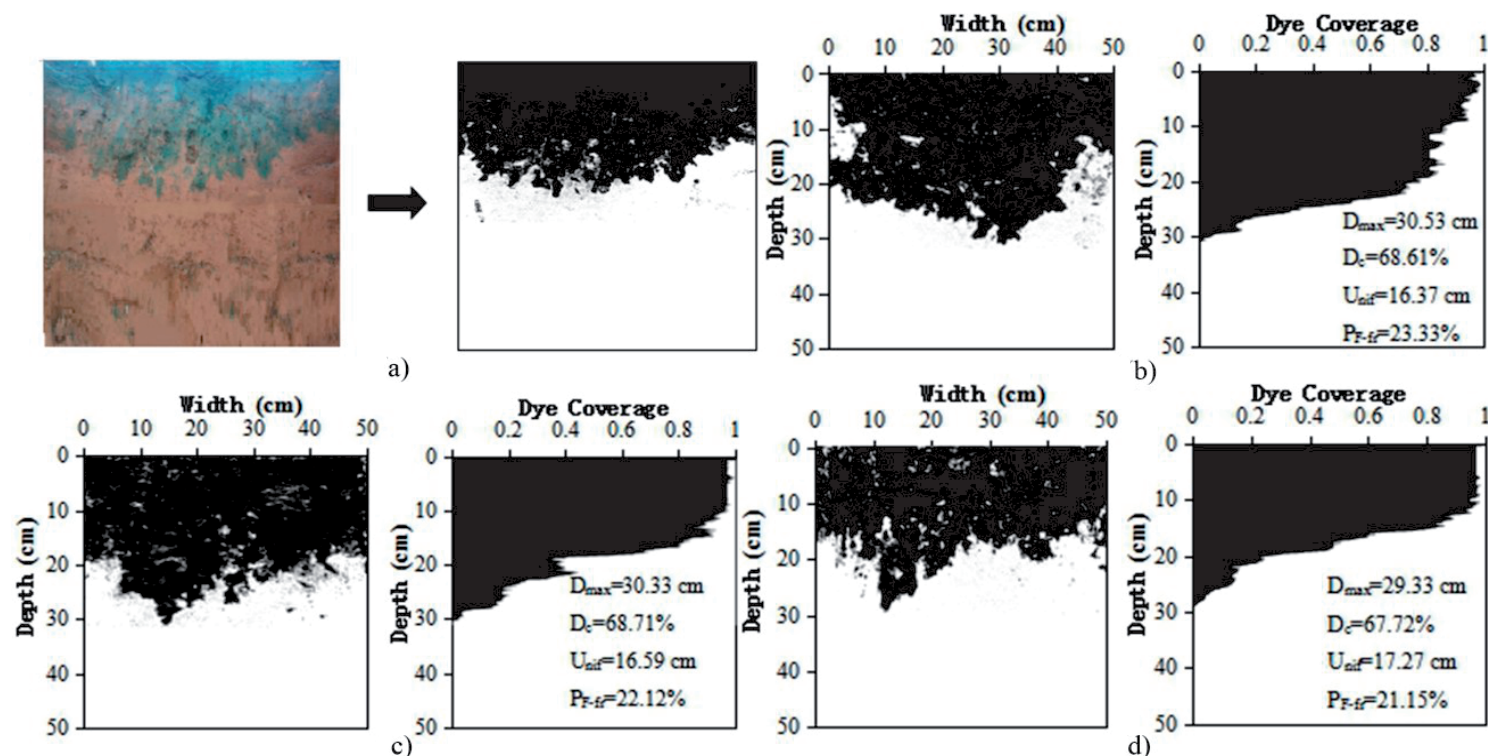

Fig. 3. The a) binary image generation graph, and binarization and vertical change in the proportion of stained area in b) I2B0, c) I2B2 and d) I2B4 treatment. 


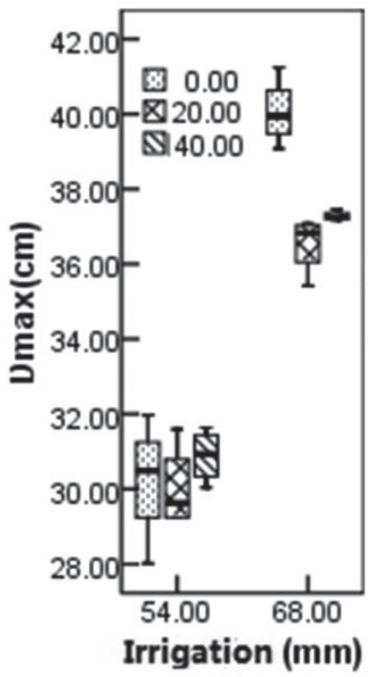

a)

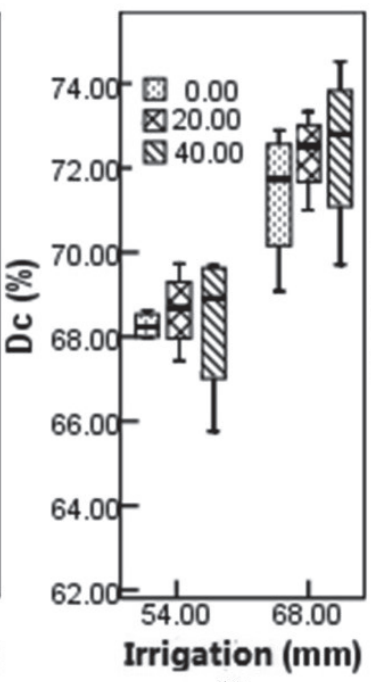

b)

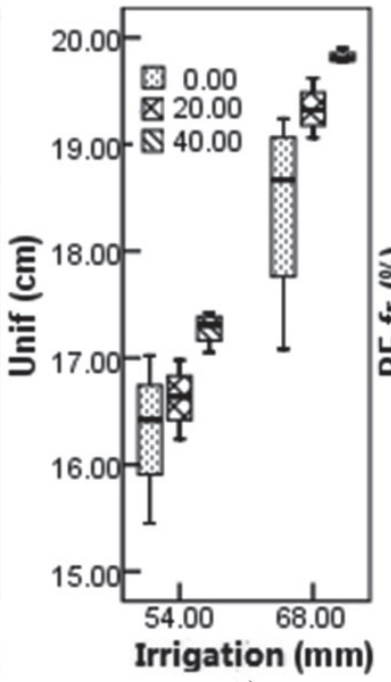

c)

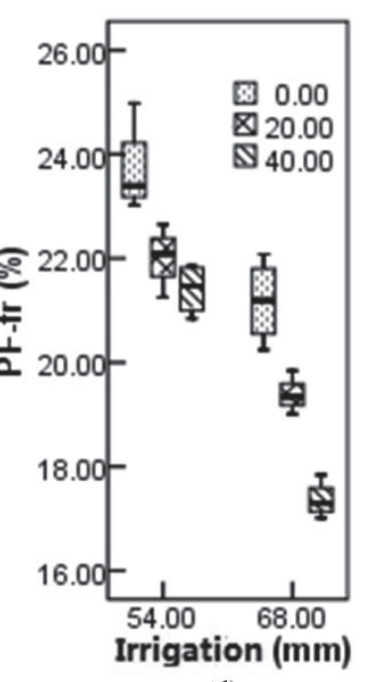

d)

Fig. 4. Boxplots of different variables measured at the different treatment: a) $D_{\max }$, b) $D_{c}$, c) $U_{n i f}$, d) $P_{F-f r}$.

indicated that preferential flow decreased with increasing biochar application rates under the tested amount of biochar application.

There were significant differences for the four indexes among different treatments $(p=0.02 \sim 0.05)$, which indicated that the preferential flow patterns of soil under different treatments were different and had statistical significance. All parameters used in this study showed the same overall trend (Fig. 4). Except for $P_{F-f r}$, the values of the other parameters under high irrigation were larger than those under low irrigation. The distribution trend of the parameters under low irrigation is the same to that under high irrigation. For this reason, limited our discussion to the high irrigation treatment. The $D_{c}$ values in the I3B4 $(72.3 \%)$ and I3B2 (72.1\%) plots were larger than those in the I3B0 (71.7\%) plots (Fig. 4b). The $U_{n i f}$ was $199 \mathrm{~mm}$ in the I3B4, a value significantly higher than those in the I3B2 and I3B0 plots, which were significantly different from each other (193 and $184 \mathrm{~mm}$, respectively). In contrast, in the I2B0 plots, preferential flow was initiated earlier as shown by the shallower uniform infiltration depths. The $P_{F-f r}$ indicated that only $17.3 \%$ of the stained area corresponded to the preferential flow pathways in the I3B4. In contrast, this value increased to $19.3 \%$ and $21.5 \%$ in $\mathrm{I} 3 \mathrm{~B} 2$ and $\mathrm{I} 3 \mathrm{~B} 0$, respectively (Fig. 4d). This difference indicates that a larger fraction of the infiltrating water in the I3B0 was channelized through preferential pathways. However, there was no obvious distribution characteristic of the $D_{\max }$ in the six plots, but it showed internal heterogeneity (Fig. 4a).

\section{Effect of Biochar on the Soil Properties}

Biochar-amended soils had $(\mathrm{p}<0.05)$ higher field capacity $(F C)$, soil organic carbon $(S O C)$, lower cation exchange capacity $(C E C)$ and lower bulk density $(B D)$, in contrast to non-amended soil (Table 1). And irrigation showed no effect on soil properties. In high irrigation treatment, $21.2 \%$ higher $F C, 14.8 \%$ higher $C E C, 186.4 \%$

Table 1. Effect of biochar on selected soil properties (mean \pm SE, $n=9)$.

\begin{tabular}{|c|c|c|c|c|c|}
\hline \multirow{2}{*}{\multicolumn{2}{|c|}{ Treatment }} & $F C$ & $B D$ & $C E C$ & SOC \\
\hline & & $\%$ & $\mathrm{~g} / \mathrm{cm}^{3}$ & $\mathrm{cmol} / \mathrm{kg}$ & $\mathrm{g} / \mathrm{kg}$ \\
\hline \multicolumn{2}{|c|}{ ILB0 } & $17.00 \pm 1.56 \mathrm{~b}$ & $1.53 \pm 0.06 \mathrm{a}$ & $11.90 \pm 0.68 \mathrm{~b}$ & $5.42 \pm 0.68 \mathrm{~b}$ \\
\hline \multicolumn{2}{|c|}{ ILB2 } & $20.62 \pm 1.06 \mathrm{a}$ & $1.47 \pm 0.03 \mathrm{~b}$ & $13.70 \pm 0.55 \mathrm{a}$ & $19.56 \pm 2.45 \mathrm{a}$ \\
\hline \multicolumn{2}{|c|}{ IHB0 } & $17.73 \pm 1.23 \mathrm{~b}$ & $1.51 \pm 0.05 \mathrm{a}$ & $12.10 \pm 1.61 \mathrm{ab}$ & $7.19 \pm 0.96 \mathrm{~b}$ \\
\hline \multicolumn{2}{|c|}{ IHB2 } & $21.48 \pm 1.38 \mathrm{a}$ & $1.44 \pm 0.03 \mathrm{~b}$ & $13.90 \pm 0.49 \mathrm{a}$ & $20.59 \pm 2.54 \mathrm{a}$ \\
\hline \multirow{3}{*}{ ANOVA $†$} & I & n.s. & n.s. & n.s. & n.s. \\
\hline & B & $* *$ & $*$ & $*$ & $* *$ \\
\hline & $\mathrm{I} \times \mathrm{B}$ & n.s. & n.s. & n.s. & n.s. \\
\hline
\end{tabular}

$\dagger$ n.s. - no significance, ${ }^{*}$ - significant at $\mathrm{P}<0.05,{ }^{*}$ - significant at $\mathrm{P}<0.01$. Values are average of nine replications. Means followed by different letters within each sample are significantly different at 0.05 . 


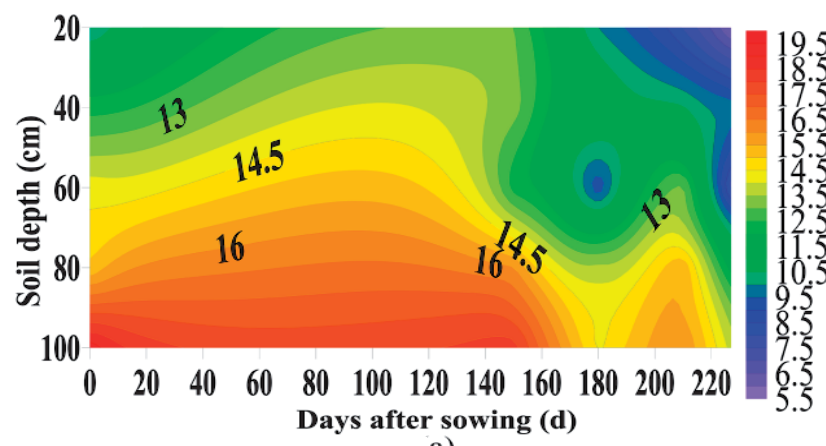

a)

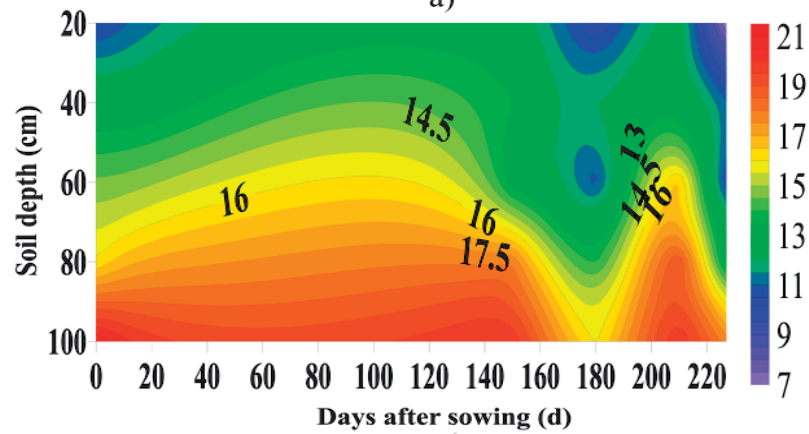

c)

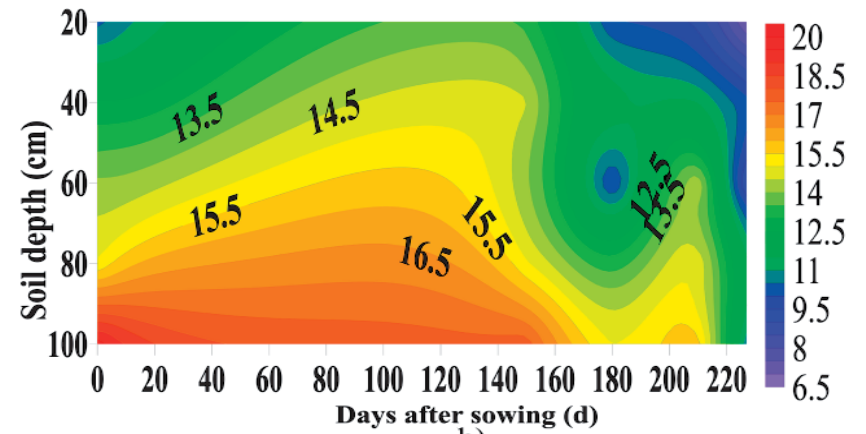

b)

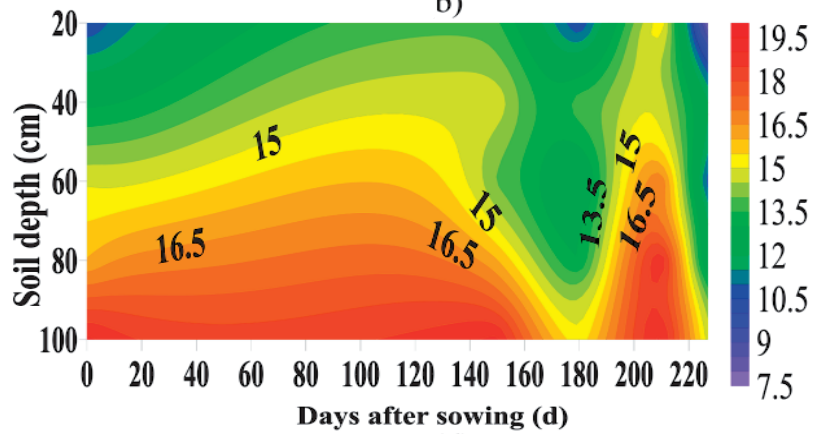

d)

Fig. 5. Soil water content (\%) in plots of a) ILB0, b) ILB2, c) IHB0 and d) IHB2 treatment at jointing (17 March, 152 days after sowing), heading (15 April, 181 days after sowing), grain filling (13 May, 209 days after sowing), and harvesting stages (01 June, 228 days after sowing).

higher $S O C$, and $4.6 \%$ lower $B D$ were found at the plough layer soil $(0 \sim 0.6 \mathrm{~m})$ with biochar application, as compared with the treatment without biochar. Similarly, in low irrigation treatment, $F C, C E C$, SOC were $21.3 \%$, $15.1 \%, 260.9 \%$ higher and $B D$ was $3.9 \%$ lower than non-amended plough layer soil.

As the carrier of nutrient transport, water is closely related to the distribution and accumulation of nutrients. Dynamics of soil water contentc $(S W C)$ in ILB0, IHB0, ILB2, and IHB2 plots during the experiment are shown in Fig. 5. It can be seen from the figure that the change rule of $S W C$ with depth during the winter wheat planting period is roughly the same. The $S W C$ of $0.4 \sim 0.6 \mathrm{~m}$ soil layer appears a trough, which is mainly due to the absorption of crop roots, while the $S W C$ reaches the peak value at the $0.6 \sim 1.0 \mathrm{~m}$ soil layer, mainly because there are many small particles in the layer. After the first two irrigation, it was found that biochar had comparatively higher $S W C(0 \sim 0.6 \mathrm{~m})$ in ILB2 and IHB2 with respect to non-amended treatments. After irrigation at the filling stage and at the harvesting stage, the $S W C(0 \sim 0.6 \mathrm{~m})$ increased significantly in the order of IHB2 $(15.69,10.23)>\operatorname{IHB} 0(14.06,9.53)>\operatorname{ILB} 2(11.73$, 8.68)>ILB0 (10.57, 7.84).
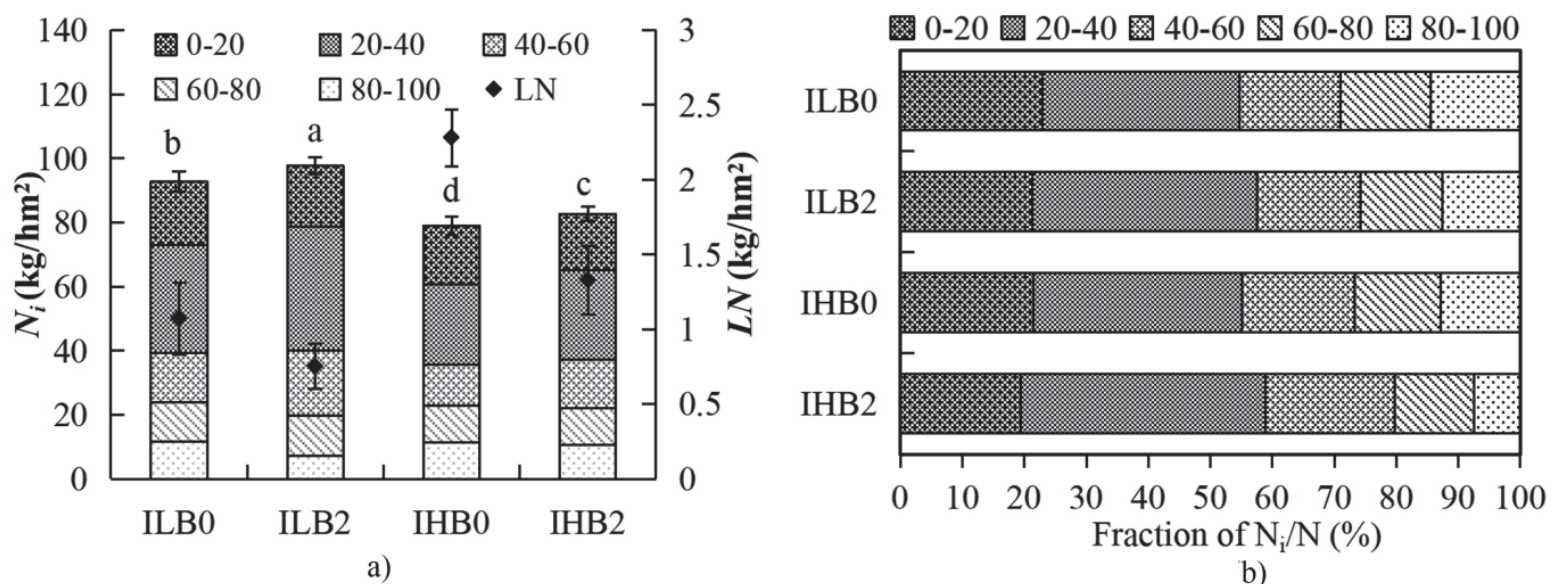

Fig. 6. Effect of biochar application (B) and irrigation amount (I) on the a) residual $\mathrm{NO}_{3}^{-}-\mathrm{N}$ accumulation $\left(N_{i}\right), \mathrm{NO}_{3}^{-}-\mathrm{N}^{-}$leaching loss $(L N)$ and b) fraction of $\mathrm{NO}_{3}^{-}-\mathrm{N}$ in different soil layers. 
Table 2. Effect of biochar application (B) and irrigation amount (I) on aboveground dry biomass (DB, t/hm²), effective panicles per square meter (EP, ear), grain number per spike (SG, grain), filled ear length (EL, cm), thousand kernel weight (TKW, g), yield $\left(\mathrm{Y}, \mathrm{kg} / \mathrm{hm}^{2}\right.$ ), water use efficiency (WUE, $\mathrm{kg} / \mathrm{hm}^{2} / \mathrm{mm}$ ) and nitrogen partial factor productivity (NPFP, $\mathrm{kg} / \mathrm{kg}$ ).

\begin{tabular}{|c|c|c|c|c|c|c|c|c|c|}
\hline \multirow{2}{*}{\multicolumn{2}{|c|}{ Treatment }} & \multirow{2}{*}{ DB } & \multicolumn{4}{|c|}{ Yield components } & \multirow{2}{*}{ Y } & \multirow{2}{*}{$W U E$} & \multirow{2}{*}{$N P F P$} \\
\hline & & & $E P$ & $S G$ & $E L$ & $T K W$ & & & \\
\hline \multicolumn{2}{|c|}{ ILB0 } & $\begin{array}{c}17.65 \pm 1.45 \\
\mathrm{c}\end{array}$ & $392 \pm 2.32 \mathrm{c}$ & $32.41 \pm 0.68 \mathrm{c}$ & $6.87 \pm 0.02 \mathrm{~b}$ & $\begin{array}{c}52.75 \pm 0.04 \\
\mathrm{~b}\end{array}$ & $6684.88 \pm 20.70 \mathrm{~d}$ & $\begin{array}{c}18.32 \pm 0.02 \\
\mathrm{c}\end{array}$ & $\begin{array}{c}26.22 \pm 0.08 \\
\mathrm{~d}\end{array}$ \\
\hline \multicolumn{2}{|c|}{ ILB2 } & $\begin{array}{c}21.42 \pm 0.70 \\
b\end{array}$ & $421 \pm 7.81 \mathrm{~b}$ & $34.55 \pm 0.50 \mathrm{~b}$ & $7.15 \pm 0.06 \mathrm{a}$ & $\begin{array}{c}53.96 \pm 0.54 \\
b\end{array}$ & $7488.45 \pm 99.17 \mathrm{c}$ & $\begin{array}{c}20.86 \pm 0.03 \\
\mathrm{a}\end{array}$ & $\begin{array}{c}29.37 \pm 0.39 \\
\text { c }\end{array}$ \\
\hline \multicolumn{2}{|c|}{ IHB0 } & $\begin{array}{c}22.69 \pm 0.42 \\
b\end{array}$ & $\begin{array}{c}432 \pm 12.23 \\
b\end{array}$ & $\begin{array}{c}35.34 \pm 0.25 \\
\mathrm{ab}\end{array}$ & $7.27 \pm 0.02 \mathrm{a}$ & $\begin{array}{c}54.75 \pm 0.03 \\
\mathrm{a}\end{array}$ & $\begin{array}{c}8351.29 \pm 136.73 \\
\text { b }\end{array}$ & $\begin{array}{c}20.52 \pm 0.06 \\
\text { b }\end{array}$ & $\begin{array}{c}32.75 \pm 0.54 \\
\mathrm{~b}\end{array}$ \\
\hline \multicolumn{2}{|c|}{ IHB2 } & $\begin{array}{c}25.67 \pm 0.81 \\
\mathrm{a}\end{array}$ & $440 \pm 5.29 \mathrm{a}$ & $35.77 \pm 0.49 \mathrm{a}$ & $7.21 \pm 0.03 \mathrm{a}$ & $\begin{array}{c}55.54 \pm 0.58 \\
\mathrm{a}\end{array}$ & $8722.29 \pm 72.19 \mathrm{a}$ & $\begin{array}{c}21.41 \pm 0.07 \\
\mathrm{a}\end{array}$ & $\begin{array}{c}34.21 \pm 0.28 \\
\mathrm{a}\end{array}$ \\
\hline \multirow{3}{*}{ ANOVA } & B & $* *$ & $* *$ & $* *$ & $* *$ & $* *$ & $* *$ & $* *$ & $* *$ \\
\hline & I & $* *$ & $* *$ & $* *$ & $* *$ & $* *$ & $* *$ & $* *$ & $* *$ \\
\hline & $\mathrm{B} \times \mathrm{I}$ & $*$ & $* *$ & $* *$ & $* *$. & $* *$. & $* *$ & $* *$ & $* *$ \\
\hline
\end{tabular}

The biochar application (B) and irrigation amount (I) influenced $\mathrm{NO}_{3}^{-}-\mathrm{N}$ residue and leaching loss during the whole growth period of winter wheat (Fig. 6a). These results indicated that the residual $\mathrm{NO}_{3}^{-}-\mathrm{N}$ decreased increasing irrigation, which may be due to the increase of nitrogen absorption by winter wheat under suitable irrigation. These results indicated that the leaching loss decreased with the biochar application. Meanwhile, it was found that the application of biochar could reduce leaching concentration at the same irrigation level, thus increasing the residual nitrogen in the soil. Under the same irrigation conditions, the proportion of residual $\mathrm{NO}_{3}-\mathrm{N}$ accumulation in $0 \sim 0.6 \mathrm{~m}$ soil layer to that in $0 \sim 1.0 \mathrm{~m}$ soil layer increased significantly (Fig. 6b), which indicated that application of biochar can increase the capacity of the soils to retain nutrients and the time for crops to absorb nutrients.

\section{Effect of Biochar on Biomass, Yield Components WUE and NPFP}

The yield components assessment of wheat involved determining dry shoot biomass $(D B)$, effective panicle number $(E P)$, single grain number $(S G)$, filled ear length $(E L)$, and thousand kernel weight $(T K W)$. As shown in Table 2, I, B and interactions of $\mathrm{B} \times \mathrm{I}$ significantly affected all parameters. Under the low irrigation, biochar application significantly increased $D B, E P, S G, E L$, and $T K W$ by $21.4 \%, 7.4 \%, 6.6 \%$, $4.1 \%$, and $2.3 \%$, respectively. Under the high irrigation, biochar application significantly increased $D B, E P$, $S G, E L$, and $T K W$ by $13.1 \%, 1.8 \%, 1.2 \%,-0.8 \%$ and $1.4 \%$, respectively. In summary, the results indicated that biochar could greatly improve many factors that directly influence yield, especially at lower irrigation. It is found that the descending sequence of yield and NPFP of wheat with different irrigation and biochar was IHB2, IHB0, ILB2, ILB0. This proves that filling water is necessary in increasing wheat yield and the water retention gains provided by biochar were not sufficient to overcome drought stress in the filling stage. More significantly, however, the WUE of ILB2 was higher than that of IHB0, its yield was lower than that of IHB0.

\section{Discussion}

\section{Preferential Flow as Hot Spots of Soil Nutrient Cycle}

Previous studies have put forward that soil drying cracks were the main route of soil nutrient leaching, which mainly occurs in drought and fallow periods $[26,27]$. Other studies also confirmed that most of the nitrate ions will infiltrate rapidly with the preferential flow. For example, Wang [28] studied the effect of preferential flow on nitrate nitrogen migration by the method of packing soil columns, and the results showed that larger quantities of nitrate nitrogen migrated under the promotion of soil preferential flow. Wu et al. [29] showed that the development of preferential flow in farmland would increase the infiltration recharge of groundwater and reduce the utilization efficiency of irrigation and rainfall. Thus, once the cracks form preferential flow pathways, they could control the overall nutrient losses from soil-plant systems. In this study, the preferential flow of soil in the study area was found through the analysis of tracer staining profile (Fig. 3).

$\mathrm{Qu}$ et al. [30] and Geng et al. [31] simulated the effects of straw returning on preferential flow and the leaching of nitrogen, phosphorus, and potassium nutrients through soil column test. The results showed that the contents of nitrogen, phosphorus, and potassium in the leaching solution decreased to varying 
degrees, and the leaching loss in the blank test was 2.79 4.54 times those of the straw returning treatments. Therefore, previous studies on preferential flow only showed that the existence of preferential flow and the existence of preferential flow led to the rapid leaching of nutrients, but the focus of this study is to explore a soil conditioner that can reduce preferential flow. The result indicated that biochar application reduced preferential flow $(p<0.05)$ during irrigation, especially under high irrigation (Fig. 4). And the degree of preferential flow decreased with the increase of biochar application rates. Hence, our first hypothesis was fulfilled in term of reducing the degree of preferential flow in the soil with biochar application. Considering the cost of biochar and the effect of resistance and control, we choose the biochar application rate of $20 \mathrm{t} / \mathrm{hm}^{2}$ for the field experiment.

\section{Roles of Biochar in Soil Nutrient Cycle}

In this study, Fig. 6a) illustrated the application of biochar can reduce leaching concentration and increase the residual nitrogen in the soil. Meanwhile, Fig. 6b) also indicated that application of biochar can increase the capacity of the soils to retain nutrients and the time for crops to absorb nutrients. To investigate its reason, previous studies have shown that the effects of biochar on nutrient leaching clearly depend on the complex chemical, physical, and biological processes. Soil bulk density is considered as the main driving force of soil physical properties, which describes the potential functions of soil in aeration, water infiltration, as well as water and gas movement. In this study, a $4.6 \%$ and $3.9 \%$ decrease in soil bulk density was observed after a wheat growing season of biochar application under the condition of low and high irrigation respectively (Table 1), which is consistent with the results of other studies [32]. For example, Arthur and Ahmed [33] applied straw biochar to rough tropical soils and reported a significant decrease in soil bulk density (32\%) after three months of straw biochar application. From an agronomic point of view, higher biochar doses improved water retention and available water and increased field water holding capacity, corroborating other studies on this material [34-36]. In our study, biochar application significantly increased the field capacity from about $17.00 \%$ to $20.00 \%$ (Table 1 ), increasing the availability and storage of water (Fig. 5) and reducing the risk of drainage (Fig. 6). Fig. 5 analyzed biochar-amended soils had higher water content in contrast to non-amended control soil, although irrigation have greater effect than biochar application on water content. In terms of improvement performance, there was slighter response on soil water content by biochar application in high irrigation treatment with respect to that in low irrigation treatment. In addition, our study has shown that biochar application could significantly improve soil CEC (Table 1). The above conclusion is consistent with those of Deenik and Cooney [37], which proved that biochar application could improve soil fertility by increasing the $C E C$ and consequently the retention and availability of nutrients for plants. Finally, we also explored the effect of biochar application on soil organic carbon, and the results showed an increase in the content of organic carbon in the soil, thus enhanced the adsorption performance of the soil. The above conclusion was consistent with that of $\mathrm{Bi}$ et al. [38], which proved that biochar application reduced the content of nitrate nitrogen in the soil leaching solution due to the increase in the content of soil organic carbon.

The results of this study showed that the contents of nitrate nitrogen in the leaching solution of the treatments with biochar application were lower than those of the non-amended controls (Fig. 6), indicating that the application of biochar had a certain inhibition on the leaching of soil nitrogen. Increasing the retention of these nutrients in soil profiles will increase the possibility of nutrients being absorbed by plant roots, thereby reducing the risk of leaching and transporting to the surface or underground. This study demonstrated the causes of this phenomenon from two aspects. On the one hand, as in previous studies, we have also proved that biochar can reduce the leaching of water and nutrients from soil properties. On the other hand, preferential flow was the main way of nitrate leaching, while this study proved that the application of biochar could reduce the preferential flow. In conclusion, biochar application can reduce nutrient loss and groundwater pollution.

\section{Enhanced Yield, and Water and Fertilizer Use Efficiency}

Biochar application promoted higher shoot biomass, effective panicle number, single grain number, and yield of winter wheat (Table 2). Our results showed that biochar application increased the yield by $12.0 \%$ and $4.4 \%$ under low irrigation and high irrigation, respectively. Similarly, Yan et al. [39] reported that the winter wheat yield was increased over the next two years with $40 \mathrm{t} / \mathrm{hm}^{2}$ biochar application, but they considered that biochar application potentially improved the yield by increasing the soil temperature. Additionally, biochar application contributed to the increase of fertilizer efficiency. Under the same irrigation and fertilization conditions, nitrogen productivity $(N P F P)$ can be increased by $12 \%$ due to the application of biochar (Table 2), which is consistent with the result of Dong [40]. Meanwhile, application of biochar significantly increased plant water status as exemplified by the improved water use efficiency. Liu et al. [41] have also found that biochar increased water availability to plants. In this study, despite the higher water retention values in treatments containing biochar, it was not sufficient to meet the water needs of winter wheat under low irrigation conditions. Previous studies have shown that the effects of biochar on plant growth depend on the interaction of various factors. It has been 
reported that biochar influences plant growth indirectly by affecting soil physical and chemical properties, microbial activities [42, 43], soil structure [32, 44], and nutrient cycling $[45,46]$. Based on the results of the study, our study suggested that the biochar added to soil increased the capacity of the soils to retain nutrients and winter wheat productivity.

\section{Conclusions}

The study was conducted to assess the effect of biochar on preferential flow and soil structure, water and nutrient use efficiency, and the growth response of winter wheat in the North China Plain. Our results revealed that the degree of preferential flow was decreased with the increase of biochar application within the designed biochar application rates, especially under high irrigation, but the decreasing speed slowed down significantly. The field trial results proved that increasing biochar application rates significantly increased field capacity, bulk density, soil organic carbon, and reduced cation exchange capacity of the plough layer soil $(0 \sim 60 \mathrm{~cm})$. All these factors are critical for improving soil health. In addition, our results clearly demonstrated that adding biochar to soil under the same irrigation improved the yield of winter wheat. But, wheat productivity under the ILB2 treatment were still below that under the IHB0. It was indicated that the water retention gains provided by biochar were not sufficient to overcome the adverse effect from drought stress in the soil. Moderate water supply during the flowering to fruit set stage had a significantly positive effect on the wheat yield. Therefore, the optimal treatment involved controlling irrigation quota to be $0.8 E T$ and biochar application rate to be $20 \mathrm{t} / \mathrm{hm}^{2}$.

In conclusion, the results of this study strongly supported the hypothesis that biochar application would reduce the soil preferential flow and revealed that biochar had positive influence on soil properties and winter wheat production. Therefore, under the background of nitrogen fertilizer reduction, application of biochar might be a promising approach for reducing soil nitrogen leaching, improving water and fertilizer use efficiency and promoting crop productivity.

\section{Acknowledgments}

The authors acknowledge 'Thirteenth Five-Year Plan' National key R \& D projects (2017YFD0800601-02) for financially supporting this research. The authors also appreciate the anonymous reviewers and editors for their contributions and help in this research.

\section{Conflict of Interest}

The authors declare no conflict of interest

\section{References}

1. YUAN Z.J., SHEN Y.J. Estimation of agricultural water consumption from meteorological and yield data: A case study of Hebei, North China. PLoS One, 8 (3), e58685, 2013.

2. MUELLER N.D., GERBER J.S., JOHNSTON M., RAY D.K., RAMANKUTTY N., Foley J.A. Closing yield gaps through nutrient and water management. Nature, 494 (7437), 390, 2013.

3. WANG S.Q., WEI S.C., LIANG H.Y., ZHENG W.B., LI X.X., HU C.S., CURRELL M.J., ZHOU F., MIN L.L. Nitrogen stock and leaching rates in a thick vadose zone below areas of long-term nitrogen fertilizer application in the North China Plain: A future groundwater quality threat. Journal of Hydrology, 576, 28, 2019.

4. NIU X.S., ZHANG C., JU X.T. Mechanism of nitrogen leaching in fluvo-aquic soil and deep vadose zone in the North China Plain. Chinese Journal of Eco-Agriculture, 29 (1), 53, 2021.

5. STAMM C., FLÜHLER H., GÄCHTER R., LEUENBERGER J., WUNDERLI H. Preferential transport of phosphorus in drained grassland soils. Journal of Environmental Quality, 27 (3), 515, 1998.

6. OHRSTROM P., PERSON M., ALBERGEL J., ZANTE P., NASRI S., BERNDTSSON R., OLSSON J. Fieldscale variation of preferential flow as indicated from dye coverage. Journal of Hydrology, 257, 164, 2002.

7. YAN J.L., ZHAO W.Z., ZHANG Y.Y. Characteristics of the preferential flow and its response to irrigation amount in oasis cropland. Chinese Journal of Applied Ecology, 26 (5), 1454, 2015.

8. FLURY M. Dyes as tracers for vadose zone hydrology. Reviews of Geophysics, 41 (1), 1002, 2003.

9. GERMÁN-HEINS J., FLURY M. Sorption of brilliant blue FCF in soils affected by $\mathrm{pH}$ and ionic strength. Geoderma, 97 (1), 87, 2000.

10. FU S.F., XU Y., NIU S.W., DU L.Y., JIANG M.H., GUO K., SUN L.J. Research progress of control measures for soil $\mathrm{N}$ leaching in dry farmland. Environmental Science \& Technology, 43 (6), 161, 2020.

11. LEHMAN J., RILLIG M.C., THIES J., MASIELLO C.A., HOCKADAY W.C., CROWLEY D. Biochar effects on soil biota-A review. Soil Biology \& Biochemistry, 43 (9), 1812, 2011.

12. HASAN O.Z. A new approach to soil solarization: addition of biochar to the effect of soil temperature and quality and yield parameters of lettuce (Lactuca sativa L. Duna). Scientia Horticulturae, 228, 153, 2017.

13. LAIRD D.A., FLEMING P., DAVIS D.D., HORTON R., WANG B., KARLEN D.L. Impact of biochar amendments on the quality of a typical Midwestern agricultural soil. Geoderma, 158 (3), 443, 2010.

14. KOCH S., KAHLE P., LENNARTZ B. Visualization of colloid transport pathways in mineral soils using titanium (IV) oxide as a tracer. Journal of Environmental Quality, 45 (6), 2053, 2016.

15. FLURY M. Dyes as tracers for vadose zone hydrology. Reviews of Geophysics, 41 (1), 1002, 2003.

16. SCHAIK N.L.M.B.V. Spatial variability of infiltration patterns related to site characteristics in a semi-arid watershed. Catena, 78 (1), 36, 2009.

17. BARGUÉS TOBELLA A., REESE H., ALMAW A. BAYALA J., MALMER A., LAUDON H., ILATEDT U. The effect of trees on preferential flow and soil infiltrability 
in an agroforestry parkland in semiarid Burkina Faso. Water Resources Research, 50 (4), 3342, 2014.

18. GAO X.Y., LIU T.X., DUAN L.M., TONG X. Determination and effect of dune-meadow field capacity in the Horqin sandy land. Arid Zone Research, 33 (6), 1336, 2016.

19. SHAO M.A., WANG Q.J., HUANG M.B. Soil physics. Beijing: Higher Education Press, 37-38, 84, 142, 2006.

20. GE S.F., PENG L., REN Y.H., JIANG Y.M. Effect of straw and biochar on soil bulk density, cation exchange capacity and nitrogen absorption in apple orchard soil. Scientia Agricultura Sinica, 47, 366, 2014.

21. LU R.K. Analytical methods for soil and agricultural chemistry. Beijing: China Agricultural Science and Technology Press, 269, 1999.

22. ZHU X.C., CAO R.X., SHAO M.A. Spatial simulation of soil-water content in dry and wet conditions in a hectometer-scale degraded alpine meadow. Land Degradation \& Development, 30, 278, 2018.

23. WALKLEY A., BLACK I.A. An examination of the Degtjareff method for determining soil organic matter, and a proposed modification of the chromic acid titration method. Soil Science, 37, 29, 1934.

24. BREMNER J.M. Determination of nitrogen in soil by the Kjeldahl method. Journal of Agricultural Science, 55 (1), 11,1960

25. BAO S.D. Soil agrochemical analysis, 3rd edn. Beijing: China Agriculture Press, 132, 2000.

26. ZHANG Z.B., PENG X., WANG L.L., ZHAO Q.G., LIN $\mathrm{H}$. Temporal changes in shrinkage behavior of two paddy soils under alternative flooding and drying cycles and its consequence on percolation. Geoderma, 192, 12, 2013.

27. JANSSEN M., LENNARTZ B., WÖHLING T. Percolation losses in paddy fields with a dynamic soil structure: model development and applications. Hydrological Processes, 24 (7), 813, 2010.

28. WANG B.Y. The characteristics of preferential flow pathways and its effect on nitrate nitrogen migration in farmland soil at Changping district in Beijing. Master degree papers, Beijing Forestry University, Beijing, 2013.

29. WU Q.H., ZHANG W., LIN W.J., ZHANG F.W., WANG G.L. The estimation of groundwater recharge and preferential flow based on the applied tracers: a case study of Luancheng and Hengshui areas in Hebei Province. Acta Geosciencea Sinica, 35, 495, 2014.

30. QU Z.Q., JIA L.Q., JIN H.Y., JIANG X., ZHANG Q., GAO J.H. Macropores and preferential flow and their effects on the migration of pollutants in soil. Acta Geosciencea Sinica, 36, 341, 1999.

31. GENG Y.H., LU W.X., JIANG Y.M. Effect of soil constalk fertilization on nutrient leaching in preferential flow. Journal of Northwest A \& F University (Natural Science Edition), 35, 146, 2007.

32. HE L., ZHAO J., YANG S., ZHOU H., XING G.X. Successive biochar amendment improves soil productivity and aggregate microstructure of a red soil in a five-year wheat-millet rotation pot trial. Geoderma, 376 (5), 114570, 2020.

33. ARTHUR E., AHMED F. Rice straw biochar affects water retention and air movement in a sand-textured tropical soil. Archives of Agronomy Soil Science, 63 (14), 1, 2017.
34. EKER C., MANIRAKIZA N. Effectiveness of compost and biochar in improving water retention characteristics and aggregation of a sandy clay loam soil under wind erosion. Carpathian Journal of Earth and Environmental Science, 15 (1), 5, 2020.

35. LIMA J.R.D., SILVA W.D., DE MEDEIROS E.V., DUDA G.P., CORREAA M.M., MARTINS FILHO A.P., CLERMONT-DAUPHIN C., ANTONINO A.C.D., HAMMECKER C. Effect of biochar on physicochemical properties of a sandy soil and maize growth in a greenhouse experiment. Geoderma, 319, 14, 2017.

36. AJAYI A.E., HORN R. Comparing the potentials of clay and biochar in improving water retention and mechanical resilience of sandy soil. International Agrophysics, 30 (4), 391, 2016.

37. DEENIK J.L., COONEY M.J. The potential benefits and limitations of corn cob and sewage sludge biochars in an infertile Oxisol. Sustainability, 8 (2), 131, 2016.

38. BI Y., CAI S., WANG Y., ZHAO X., ZHU Z.L. Structural and microbial evidence for different soil carbon sequestration after four-year successive biochar application in two different paddy soils. Chemosphere, 254, 126881, 2020.

39. YAN Q., DONG F., LI J., DUAN Z.Q., YANG F., LI X., LU J.X., LI F. Effects of maize straw-derived biochar application on soil temperature, water conditions and growth of winter wheat. European Journal of Soil Science, 70 (6), 12863, 2019.

40. DONG D., WANG C., ZWIETEN L.V., WANG H.L., WU W.X. An effective biochar-based slow-release fertilizer for reducing nitrogen loss in paddy fields. Journal of Soil and Sediment, 20, 3027, 2019.

41. LIU Z., DUGAN B., MASIELLO C.A., BARNES R.T., GALLAGHER M.E., GONNERMANN H. Impacts of biochar concentration and particle size on hydraulic conductivity and DOC leaching of biochar-sand mixtures. Journal of Hydrology, 533, 461, 2016.

42. WANG D., FELICE M.L., SCOW K.M. Impacts and interactions of biochar and biosolids on agricultural soil microbial communities during dry and wet-dry cycles. Applied Soil Ecology, 152, 103570, 2020.

43. LI F., MEN S., ZHANG S., HUANG J., HUANG Z.B. Responses of low-quality soil microbial community structure and activities to application a mixed material of humic acid, biochar, and super absorbent polymer. Journal of Microbiology and Biotechnology, 30 (9), 1310, 2020.

44. FANG Y.Y., SINGH B.P., NAZARIES L., KEITH A., TAVAKKOLI E., WILSON N., SINGH B. Interactive carbon priming, microbial response and biochar persistence in a vertisol with varied inputs of biochar and labile organic matter. European Journal of Soil Science, 70 (5), 960, 2019.

45. FOSTER E.J., BAAS P., WALLENSTEIN M.D., COTRUFO M.F. Precision biochar and inoculum applications shift bacterial community structure and increase specific nutrient availability and maize yield. Applied Soil Ecology, 151, 103541, 2020.

46. YAN Q., DONG F., LI J., DUAN Z.Q., YANG F., LI X., LU J.X., LI F. Effects of maize straw-derived biochar application on soil temperature, water conditions and growth of winter wheat. European Journal of Soil Science, 70 (6), 12863, 2019. 